\title{
Intuition and evidential facts in Carnap's analysis of space
}

\author{
Intuição e fatos evidenciais na análise do espaço de
}

Carnap

JUAN BAUTISTA BENGOETXEA ${ }^{a}$

\begin{abstract}
One of the reasons for Carnap's (1922) analysis of space was the confounding status of many arguments around the state of the art on that topic at that time. The unsatisfactory views supplied by mathematicians, physicists and philosophers led Carnap to propose a new conception of space. His proposal, which employs the notion of intuition as a fundamental tool, fared better, but clashed with his conventionalists intentions derived from an allegedly tolerant attitude. The notion of intuition here examined allows us to claim that Carnap's target was also an objectivist epistemological program dependent on certain realistic reminiscences embodied in the notion of evidence or matter of fact (Tatbestand).
\end{abstract}

Keywords: Objectivity. Intuition. Conventionalism. Evidence. Tolerance.

${ }^{*}$ I would like to thank the Spanish Government's State Secretary of Research, Development and Innovation (Research Project 'Estándares de prueba y elecciones metodólogicas en la fundamentación científica de las declaraciones de salud', FFI2017-83543-P), as well as the European Commission's European Regional Development Fund (FEDER) program, for their support.

a University of the Balearic Islands, Palma, Espanha. PhD in Logic and Philosophy of Science, email: juanbautista.bengoechea@uib.cat 



\section{Resumo}

Uma das razões da análise do espaço de Carnap (1922) foi o status confuso de muitos argumentos em torno do estado da arte sobre este tópico na época. As concepções insatisfatórias fornecidas por matemáticos, físicos e filósofos levaram Carnap a propor uma nova imagem de espaço. Sua proposta, que emprega a noção de intuição como ferramenta fundamental, teve um desempenho melhor, mas colidiu com suas intenções convencionalistas derivadas de uma atitude supostamente tolerante. A noção de intuição aqui examinada nos permite afirmar que o alvo de Carnap também era um programa epistemológico objetivista dependente de certas reminiscências realistas incorporadas na noção de evidência ou questão de fato (Tatbestand).

Palavras-chave: Objetividade. Intuição. Convencionalismo. Evidência. Tolerância.

Carnap's analysis of space in his dissertation Der Raum (1922) shows that his works cannot be construed as a mere element of a Viennese logical empiricism version or as the paradigm of a narrow philosophical view close to the verificationist principle. Beyond several constants that cross through his works - a defense of conceptual analysis as the basic philosophical task, intimacy with scientific advancements, anti-metaphysical attitude-, since the 1980s some Carnapian virtues have been highlighted by new scholars ${ }^{1}$, especially his tolerant attitude when it comes to conceptualizing the world. Carnap presents explicitly his 'principle of tolerance' in The Logical Syntax of Language (CARNAP, 1934, p. 51-2) as follows: 'It is not our business to set up probibitions, but to arrive at conventions. [...] In logic, there are no morals. Everyone is at liberty to build up his own logic, i.e., his own form of language, as he wishes" (emphasis in the original) ${ }^{2}$. Carnap's tolerance is a common element in his works just before and after Der logische Aufbau der Welt (1928) [hereinafter Aufbau], established in conventionalist terms along with the use of formal logic. However, it would be exaggerated to stress this sort of tolerance in Der Raum because there is an element that moderates it in the opposite direction, namely

\footnotetext{
${ }^{1}$ Some relevant references dedicated to revisit young Carnap's philosophical works are Coffa (1991), Friedman (1999), Haack (1977), Howard (1996), Mormann (2009), Richardson (1998), Sauer (1989) and Uebel (1991).

2 In addition, Carnap recognizes that some of those prohibitions have usefully served to emphasize differences, although he claims that they "can be replaced by a definitional differentiation. In many cases, this is brought about by the simultaneous investigation (analogous to that of Euclidean and non-Euclidean geometries) of language-forms of different kinds" (CARNAP, 1934, p. 51). Twelve years before he had a tacit similar view when he began to scrutinize the concept of space.
} 
the search of a univocal concept, next to 'the given' or 'the factual', supporting an objectivist_and foundationalist_epistemological goal in the task of chasing a definition for the notion of space. This search will force Carnap to use some phenomenical elements next to a kind of philosophy that he will reject in the afterAufbau period. It is the case of Husserl's notion of intuition.

This text is divided into three general sections. Carnap's view on space, his overall conventionalist hypothesis, and the problem that generates the reference to a realist element (Tatbestand) are presented in the first section. In the second one, the key philosophical contribution of Carnap is examined, namely the intuitive space and intuition. These concepts help him account for how to make more objective any spatial knowledge, but beyond the terms of an 'extremely' tolerant conventionalism close to some relativistic theses. The third section shows that the Carnapian analysis in terms of intuition actually was aimed to substantiate an objectivist epistemology of space.

\section{Carnap's view on space in der Raum}

Advances in the study of the mathematical foundations of geometry and their connections with Einstein's theory of relativity questioned some widely accepted philosophical conclusions in the late Nineteenth and early Twentieth centuries. In particular, it was the Kantian conception of the relationship between geometry and experience that went into crisis (FRIEDMAN, 1992, p. 55). According to this (KANT, 1781, A162-163/B203-204), geometry and space serve as a transcendental a priori condition for the possibility of experience of nature as pure form of sensible intuition (FRIEDMAN, 1992, p. 123). However, both statements were incompatible with the progresses made in mathematics and physics, and that was why the main issue began to be focused from a triple perspective-mathematical, physical and philosophical-where the 'geometryexperience' relationship had to be properly fitted, beyond the Kantian account.

Among the proposed solutions, the empiricists conceived of geometry as an empirical theory whose validity had to be verified or refuted by experience. On the other hand, logicians and mathematicians argued that geometry was a purely formal 
science with no intrinsic relationship to experience (NERLICH, 1994, p. 123-38). Just the neo-Kantians tried to save part of the solution that Kant had proposed a century earlier. They recognized that advances in physics and mathematics had rebutted the strict Kantian conception ${ }^{3}$, while not admitting that the critical role of space and geometry in physics ceased to be necessary.

These new views originated some tension and confusion in the debate about geometry and space. It was a dispute with no clear boundaries, nor were the languages and approaches to geometry and space sufficiently bounded. The situation seemed to require a detailed analysis to help elucidate the meaning and scope of the concepts used in the discourse of mathematicians, physicists, and philosophers. One significant target for Carnap in Der Raum was precisely carrying out such elucidation.

\section{Space and conventionalism}

Der Raum is basically an argument for conventionalism. Carnap aims to show that the spatial structure we use in both scientific and ordinary speech is not the result of empirical research but of a conventional construction. To show it, he aims to prove that it is possible to choose a spatial structure other than the Euclidean one, but that is also suitable to describe and represent the matters of fact of experience (evidence) (Tatbestand). His alternative takes the form of the finite Riemannian spaces. This is a spatial structure (Riemannian) with a positive constant of curvature that he proposes and discusses in order to call into question the classical scientific (and commonsensical) approach that holds that our Earth is really 'round'. This is tantamount to saying that the Euclidean spatial structure is contained in 'the given'. However, according to Carnap "physical observation only establishes the topological relations" (CARNAP, 1922, p. 47); that is, only the topological relations are given or serve as evidence. We'll return to this question below.

Carnap's starting point states that Earth's surface $(\mathrm{E})$ is flat (RUNGGALDIER, 1984, p. 4). However, as this is a Riemannian assumption, it

\footnotetext{
${ }^{3}$ This view claimed that Euclidean geometry is the constitutive element of both experience and intuitive certainty (KANT, 1781, A723/B751; see FRIEDMAN, 1992, p. 181, f23).
} 
must set the constant curvature of the plane E. If this turns out to be zero, the Earth's surface would have to be interpreted as infinite, and this outcome would be based on a conventional decision that could hardly avoid conflicts with the results obtained by geodetic measurements. Hence, Carnap recurs to three stipulations. According to the first, $\mathrm{E}$ is a plane with a positive constant of curvature (CARNAP, 1922, p. 48). The second one stipulates that the constant has the same value than $\mathrm{E}$ has as a sphere - on the basis of measurements in classical Euclidean physics. Finally, the third one stipulates that the rest of the cosmos has the same constant curvature at every point and in any direction. This means that the spatial structure that Carnap selects is a homogeneous spherical one. Thus, given the chosen alternative spatial structure $(\mathrm{R})$ plus the matters of fact of experience (evidence), he establishes the new measurement scheme M (Maßsetzung) (BENGOETXEA, 1999, p. 279-80). $\mathrm{M}$ is the Carnapian expression of the conventional decision about both the unit of measurement and the conditions of its application. Since Carnap chooses a finite spherical space to describe 'our world', he must modify the classic $\mathrm{M}$ if he wants to avoid inconsistencies and conflicts with observational data.

Carnap's inquiry falls squarely within a conventionalist epistemology, although so far, he has just mentioned the relationship between conventionalism and spatial structures in the field of physical space. Later, in Der Raum, Carnap will distinguish various types of space in order to avoid the burden of the semantic confusion due to the several variants of this concept. He recognizes that "closer investigation of the question teaches us that the appearance of contradiction has only arisen because very different objects are being talked about from the different points of view" (CARNAP, 1922, p. 5). Carnap argues then that in that debate three different notions of space are managed: the formal space, the intuitive space, and the physical space-each respectively corresponds to the topological space, the projective space, and the metrical space.

\section{The formal space and some difficulties for conventionalism}


Formal space $(\mathrm{R})$ is a relational system constituted of completely indeterminate elements. This idea is taken from Grundlagen der Geometrie, where Hilbert established a theory of implicit definitions in order to axiomatize geometry. According to Hilbert, the mathematical geometry does not require intuitive (visual) images, since the mathematical meaning of laws and geometrical structures are acquired by means of purely conceptual relations ${ }^{4}$. The Hilbertian approach therefore explains that the meaning of the geometric elements is determined solely by their relational properties as they are formulated in the axioms.

Similarly, Carnap constructs $\mathrm{R}$ as the space where only the logical form is relevant because its geometry is maximally abstract and general (COFFA, 1991, p. 221). Advances in formal logic encourage Carnap to use the method of formal logic to construct R (CARNAP, 1922, p. 9). He first develops a theory of classes and relations, which makes it possible to deduce the notion of a cardinal number-the concept of equipollent concepts. Thanks to this, Carnap gets the tools to construct series, which are the key constituents to build R. In addition, and based on a purely formal deduction with no aid from intuition, he arrives at constructing a 'continuous' space.

What is not clear is the role of convention in this constructive task. If logic and mathematics-including geometry-is conventional (an idea made explicit later in Syntax (CARNAP, 1934, p. 51) but that Carnap already employs), the conventionalism should also affect the construction of the topological formal space. Nonetheless, in order to do this, he should be able to spot the possibility of constructing equally valid alternative formal topologies based upon alternative stipulations. But in Der Raum Carnap does not assign a definite meaning to this thesis, basically due to the extreme difficulty of constructing $\mathrm{R}$ on the basis of uniquely conventional stipulations, independently of any extra-systematic or empirical knowledge (RUNGGALDIER, 1984, p. 12). Therefore, Carnap derives R as a mapping into classical geometry and not in terms of a purely conventionalist construction.

\footnotetext{
${ }^{4}$ As Reichenbach (1928, p. 42) points out, "the merit of visualization consists only in the fact that it translates the logical compulsion of Euclidean geometry into a visual compulsion". See also Nerlich (1994, p. 114).
} 


\section{Physical space}

Carnap faces three questions in the section on physical space R" (CARNAP, 1922, p. 32-59): (i) which is the measurement scheme M, (ii) what is its functional relationship to formal space $\mathrm{R}$, and (iii) what is its relationship to evidence or matters of fact of experience $\mathrm{T}$. He raises the question of whether three or more physical points are collinear and recognizes that the answer cannot depend only on T. Without a conventional added stipulation (Festsetrung), the issue would be meaningless (CARNAP, 1922, p. 37). To answer to it, therefore, we must know what righteousness for the adopted convention is. Mostly, we tend to adopt a stipulation $\mathrm{M}$ that is dependent on a body determined as rigid (CARNAP, 1922, p. 33-4) $)^{5}$ Nonetheless, Carnap points out that the facts of experience can never force us to decide in the election.

$\mathrm{M}$ is therefore free, but not arbitrary: we can choose projective and metric spaces (of a formal or physical type) and a measurement scheme $\mathrm{M}$ for physical space, but the choice will depend on both practical aspects and purposes, although never necessarily on T. All that is required is (self)-consistency: once we use a space structure or a measurement procedure, we must be consistent with it and cling subsequently to the adopted conventions (REICHENBACH, 1928, p. 4). This is the origin of Carnap's tolerance. Since there are many theoretically possible measurement schemes and many possible descriptions-projective and metrically different but topologically isomorphic —of the same facts, we must be tolerant. That is, we won't prefer one or another one option just because it is more or less strictly adapted to some reality. In Der Raum, criteria for preferring one or another description of the world seem just to be pragmatic ${ }^{6}$.

\section{Difficulties with Tatbestand}

\footnotetext{
${ }^{5}$ One stipulation of this kind would define some notion of spatial distance and allow us to characterize 'rightness' in terms of geodesic principles. For an account of the status of these principles in the general relativity theory, see Geroch \& Jang (1975).

${ }^{6}$ For an analysis of the concept of a priori related to a pragmatism identified into the neoKantianism and the logical empiricism, see Mormann (2012), p. 115-7.
} 
It is not easy for Carnap to answer the question of what Tatbestand are. He proposes two-way outs, one substantive and the other negative. The first identifies T with the topological relationships in physical space R", although he does not characterize them satisfactorily. The negative answer indicates that Tatbestand are not the content of our overall experience, but only one of the two components- $\mathrm{T}$ and R-of it (CARNAP, 1922, p. 39). However, here Carnap warns us that it would be wrong to interpret ' $\mathrm{T}$ as the 'content' of physical space as opposed to R, the 'form'. He illustrates that $\mathrm{T}$ and $\mathrm{R}$ do not relate to the content and form of physical space respectively, but to the necessary form (T) and to the optional form (R), in which the socalled 'physical content' or 'experience' seems to be structured (CARNAP, 1922, p. 39).

This means that $\mathrm{T}$ is tantamount to the matter of fact insofar as they are somewhat given in a necessary and unique way that does not depend on any conventional decision. In linguistic terms, physical statements are T-statements if they refer to that part of the experience that is independent of any projective or metrical system (RUNGGALDIER, 1984, p. 17). That is evidence. The relationships allowed for these matters of facts of experience are just coincidence relationships (CARNAP, 1922, p. 38). They are applicable to points, lines, unspecified planes and space parts, and can be derived directly from the experience without the help of any conventional decision. They constitute the topological space, the unique spatial structure applied unambiguously to 'the given' immediately in experience (CARNAP, 1922, p. 39). Carnap's justification for this objectivist point takes shape in his inquiry on intuitive space and intuition.

\section{Intuitive space and objective knowledge}

Advised by the neo-Kantian Bruno Bauch 7 , in addition to clarifying the notion of space, Carnap intends to provide a philosophical solution to the problem of objectivity, here equated with that of uniqueness in the realm of the knowledge of space. The theory of relativity challenged the Kantian thesis that space is an $a$

\footnotetext{
7 For a deep study of the neo-Kantian influence on Carnap, see Friedman (1999). A recommendable text on the relationship, in an opposite time direction, between Der Raum and the Aufbau is Howard (1996), especially pp. 145-7.
} 
priori form of intuition, and it forced philosophers of the early Twentieth century to explore 'reality' by using new conceptual tools in the realm of ontology. It is on this background that Carnap proposes his distinction among spaces. The three spaces are hierarchically ordered according to their proximity to what Carnap calls 'empirical'. On the far position from the empirical stands R, with its maximally general structures (forms), without anything necessarily 'spatial' contained in them. The properly spatial instantiations appear in $R^{\prime}$ (intuitive space) and $R^{\prime \prime} . R^{6}$ is constituted by the distinctly spatial objects, which do not have the particularity typical of concrete empirical objects. Indeed, Carnap conceives of $\mathrm{R}^{`}$-objects as the essences (of objects) presented to us in intuition. Thus, Carnap is picking the notion of essence from Husserl's 'Wesenserchaunng program' or 'eidetic insight ' (CARNAP, 1922, p. 22-3).

Within each space, Carnap distinguishes in turn varieties nested according to their degree of generality and determination. At the most general level is the ndimensional topological space $\left(\mathrm{R}_{\mathrm{nt}}, \mathrm{R}_{\mathrm{nt}}^{\prime}, \mathrm{R}^{\prime \prime} \mathrm{nt}\right)$, in the middle level places the $\mathrm{n}$ dimensional projective space $\left(R_{n p}, R_{n p}^{\prime}, R^{\prime \prime}{ }_{n p}\right)$, and the less general or more specific space, the metrical one $\left(\mathrm{R}_{\mathrm{nm}}, \mathrm{R}_{\mathrm{nm}}^{\prime}, \mathrm{R}^{\prime \prime}{ }_{\mathrm{nm}}\right)$, appears in the last place. Theoretical physicist works with $\mathrm{R}^{\prime \prime}$ while the surveyor does with $\mathrm{R}$ and their properties. As noted above, the fundamental problem arises when the physicist aims to determine which of the possible Euclidean or non-Euclidean spaces is the space of our physical universe. And since the final difficulty-that linked to the issue of objectivity and to some extent to 'the given'-comes from the way of conceiving the matters of fact of experience $(\mathrm{T})$, it is the philosophical response that ultimately becomes more significant. Hence the use of a concept as intuition is fundamental in the development of intuitive space.

\section{Intuition}

Carnap uses the notion of intuition for two reasons: on the one hand, because formal space is completely general and does not serve as a basis for claiming that the geometry is about space. According to Carnap, it is crucial to provide an a priori content to geometry in order to grant its 'properly spatial' nature. 
On the other hand, Carnap sees the intuition as an aprioristic guarantee to sort topological matters of fact of experience in a unique overall metrical structure. In this sense, intuition would guarantee the possibility of constructing a metric for physical space. Intuition would be a necessary intermediary between formal and physical spaces. The key question then is this: how can we account for particularly spatial objects and relations? Here comes into play the intuition in Husserlian terms. Carnap introduces it as follows:

\begin{abstract}
Intuitive space is an order structure whose formal type we can certainly delimit conceptually but, like everything intuitable, not its particular nature. Here we can only point to contents of experience, namely to intuitively spatial forms and relations... As] Husserl has shown, we are certainly not dealing with facts in the sense of experiential reality, but rather with the essence (Eidos) of certain data which can already be grasped in its particular nature by being given in a single instance (CARNAP, 1922, p. 22).
\end{abstract}

This kind of apprehension picks up a properly spatial element that is ascribable to our ability to have a direct intuition of the properties of spatial forms. However, it also captures other intuitive modalities, such as the auditory one, which has some essential features that we also can know directly by means of Husserl's 'essential insight'. But here it should be underscored that only the intuitive apprehension of spatial objects-and their properties and relationships-serves as a basis for the possibility to make properly spatial judgments, and that apprehension appears as a real for the application of a logical structure. In this case, Carnap is pointing out that there is a primary a priori mode of apprehending that distinguishes the spatial characteristics of other types of features (chromatic, auditory, ...). This spatial eidos connects purely formal logical-mathematical structures of geometry with the experience of spatial relationships.

\title{
Limits for intuition and the intuitive structure of space
}

Carnap recognizes that there exist constraints to our knowledge of spatial forms grasped through intuition. He divides his analysis of this question in two parts (CARNAP, 1922, p. 22-31). In the first one, he tries to find out what exactly could be found in the spatial intuition. His first conclusion is clear: the intuitive understanding of space is limited, "only produces knowledge about spatial forms of 
limited magnitude" (CARNAP, 1922, p. 23). The second part consists in establishing some addition postulates in order to generate an overall structure. According to Carnap, we are free to construct a general structure from the basic forms obtained through intuition. If a certain form allows us to add another one of the same type, then it can be postulated that this addition process should be possible and endless (CARNAP, 1922, p. 23).

As noted, intuition just provides knowledge about limited regions. The iteration that is postulated would permit the connection among these forms in an unlimited way. This lack of limits for the operation wouldn't imply, however, a real infinitude or serve to decide between finite but unlimited spaces and infinite spaces. With this idea of intuition and the postulated extensions at hand, Carnap undertakes the task of discovering the structure of the intuitive space in two stages:

(Stg1) He browses over Hilbert's axioms for Euclidean geometry with the aim of finding out which ones emerge from "the intuition of a limited region" (CARNAP, 1922, p. 24).

(Stg2) He investigates into the (weaker) assumptions that can and should be added to those axioms to determine the overall structure of the intuitive space.

The resulting structure for the intuitive space can be characterized as follows: since the axioms directly given in intuition guarantee the infinitesimally Euclidean structure of intuitive space, and then the postulates connect these regions, the structure is one of a general class of three-dimensional Riemannian metrizable manifolds. This allows him to generalize the notion of metrical variety, which now turns out to be a kind of three-dimensional manifolds that permit a metric, but that do not have a defined one. This permission to have a metric makes Carnap calls it 'three-dimensional metrical intuitive space' $\left(\mathrm{S}_{3 \mathrm{~m}}\right)$, although it doesn't have, as mentioned, any particular metrical structure.

This is important due to the fact that not any topological space is metrizable. Thus, even though the matters of fact give us complete knowledge of the topological structure of physical space, we wouldn't have a guarantee to be able to univocally construct a metrical convention for physical space. It will be the structure of intuitive space that provides an a priori guarantee to establish such a metric. We shouldn't neglect the fact that it is precisely the connection to the spatial intuition 
(vs. chromatic or auditory ones, for example) which makes physical space basically spatial, while the variety of auditory tones or hues is not spatial at all. Metrical conventions will play their systematizing role only if we extend the matters of fact of experience with the a priori structure of intuitive space.

Carnap uses the tools of formal space to generalize the knowledge gained or 'given' in the intuitive space to broader structures and eventually he reaches the 'wider intuitive space' ( $\mathrm{S}_{\mathrm{nt}}$ ), which is the one containing the other possible intuitive spaces (CARNAP, 1922, p. 31). This space is the condition of possibility of any object of experience.

\title{
Conclusion: intuition for an objectivist epistemology
}

There are difficulties concerning the Kantian-like conception of the Euclidean geometry when this is understood as a geometry of the space of pure intuition. It is against this idea that Carnap develops his analysis of intuition. Euclidean geometry cannot play 'its' alleged aprioristic role because it is not uniquely determined as a form of the physical space. There are options for other equally valid geometries. This makes Carnap to wonder if any of the spaces, Euclidean or not, might actually be the only place with an a priori nature and able to ensure the objectivity of the spatial knowledge. His answer is plain:

\begin{abstract}
In $\mathrm{R}_{3 \mathrm{t}}$ (three dimensional topological intuitive space) we had a structure of intuitive space, which was constructed without using the concepts of straight line or segment congruence. We can therefore construct the corresponding structure $\mathrm{R}^{\prime \prime}{ }_{3 t}$ (three dimensional topological physical space) without having to decide about the straightness or relations of magnitude of physical lines-hence, without straightness-stipulations or metric-stipulations. The only relations required for the ordering of physico-spatial elements given by experience in such a structure are the relations of lying-in-or-on-one-another (incidence) of points, lines, surfaces, and spatial volumes. These relations between physico-spatial elements can be gathered from experience without an agreement on any choice of stipulation.

[...] We have seen that only topological space (by which we shall now always understand the three dimensional $\mathrm{R}^{\prime \prime}{ }_{3 t}$ ) univocally reproduces what lies before us in experience. Even the projective space $\mathrm{R}_{3 \mathrm{p}}$ is not univocal, since we must choose and establish a straightness stipulation for its construction, for which there are always different possibilities. And still less are we limited in the construction of a metrical spatial structure $\mathrm{R}^{\prime \prime} \mathrm{m}_{\mathrm{m}}$; there are infinitely many types here. Which type is realized in our completed structure depends on the metric we choose (CARNAP, 1922, p. 37-8).
\end{abstract}

According to Carnap, the topological space is a privileged one because what it claims to do is to divide the fully given in experience in two elements stemmed 
from two different sources. The distinction between the two elements is carried out similarly to, although not identically, how the distinction between form and content is established. But, as noted, instead of fixing this distinction, in the field of forms the task will consist in distinguishing the 'optional form' from the 'necessary form' (FRIEDMAN, 2001, p. 68-9). Therefore, since his purpose is twofold-to determine whether an empirical proposition is a proposition about facts or not, and to determine what in that proposition refers to the 'given' and what corresponds to the optional-, Carnap must decide whether the empirical proposition remains valid for all its possible formations or for all possible types of spatial structures (CARNAP, 1922, p. 39). This purpose is tantamount to see

if the content of the experiential statement is unchangeable (invariant) under one-one, continuous spatial transformations. Now this holds for all topological statements and for these only: i.e., for statements concerning incidence and connection of spatial forms, and thus for all statements with respect to the topological space $\mathrm{R}_{3 \mathrm{t}}$ and with respect to this only (CARNAP, 1922, p. 66).

Topological space and topological relationships are therefore privileged because they are univocally determined and thus constitute the element that remains invariant under transformations of a general relativistic class (HOWARD, 1996, p. 148). It seems that Carnap has found out the favorite candidate to play the role of the a priori form of pure intuition. It is the connection with 'the given' or matters of fact (some evidence) that gives the topological space that same nature, considering that Carnap call the necessary and unambiguous experience 'the given'. This is the experience that does not depend on freely chosen stipulations: "only the spatial determinations contained in matters of fact can be conditions for the possibility of experience. And these, as we have seen, are only the topological, but not the projective and above all not the metrical relations" (CARNAP, 1922, p. 65). Therefore, the topological is what happens a priori, since it is univocally determined as invariant in our experience of spatial relationships. In an evocative extract, Carnap states:

In treating this question it has often been correctly pointed out that this 'transcendental function' of space-the grounding of experience-can be attributed only to a unique space-form, and that therefore the non-Euclidean space-forms could not be considered for this purpose. From this 
correct assertion it should not, however, be concluded that therefore only Euclidean space can assume this role. For this space is on a par with the others and possesses as littler or as much uniqueness as any of the non-Euclidean spaces-the one, say, with a constant curvature of -20-. Rather, the correct inference from our premise can issue only in topological space, for only the latter is both superordinate to these and also completely unique: the matters of fact of experience cannot appear in several different topological forms (CARNAP, 1922, p. 66).

Hence, for Carnap 'the given' or 'the factual' is the topological because only the latter is determined univocally, an idea that he sets at risk but supported by Einstein, Schlick, Petzoldt and Cassirer (CARNAP, 1922, p. 39). ${ }^{8}$ Compared to Cassirer, for whom general relativity takes up again the Kantian pure intuition thesis-but this time in terms of coincidence-, ${ }^{9}$ Carnap employs a more sophisticated logical-mathematical tools that allow him to assert that what assigns R'3t its status of a priori form is the fact that just this sort of space is the univocal and necessary form in which our experience of spatial relationships occurs. However, as it was unclear how logic and mathematics could play the required objectifying role, Carnap used intuition insofar as it was accepted that just the former was - not logic-provided what is essential in phenomena. In this sense, and unlike his subsequent texts, Der Raum also develops a phenomenological epistemology.

\section{References}

BENGOETXEA, J.B. Representación implícita y nada que representar: Crítica al Der Raum de Carnap. In: FALGUERA, J. L., RIVAS, U., SAGÜILLO, J.M. (eds.). La filosofía analítica en el cambio de milenio. Santiago de Compostela: Universidad de Santiago de Compostela, 1999. p. 273-283.

CARNAP, R. Der Raum: Ein Beitrag zur Wissenschaftlehre. Vaduz: Topos Verlag, 1922 (1978).

CARNAP, R. The Logical Construction of the World and Pseudoproblems in Philosophy. Chicago: Open Court, 1928 (2005).

CARNAP, R. The Logical Syntax of Language. London: Routledge \& Kegan, 1934 (1971).

CASSIRER, E. Einstein's Theory of Relativity. New York: Dover, 1921 (1953).

\footnotetext{
8 Particularly, he refers to Albert Einstein's Die Grundlage der allgemeinen Relativitätstheorie (1916), Ernst Cassirer's Einstein's Theory of Relativity (1921), Joseph Petzoldt's Die Stellung der Relativitätstheorie in der geistigen Entwicklung der Menschheit (1920), and Moritz Schlick's Allgemeine Erkenntnislehre (1918).

${ }^{9}$ The general theory of relativity reduces the content and form of laws of nature to this concept, so that relativity satisfies the idea of unity of nature and of its univocal determination (CASSIRER, 1921, p. 417).
} 
COFFA, J. A. The Semantic Tradition from Kant to Carnap: To the Vienna Station. Cambridge: Cambridge University Press, 1991.

FRIEDMAN, M. Foundations of Space-Time Theories: Relativistic Physics and Philosophy of Science. Princeton, NJ: Princeton University Press, 1983.

FRIEDMAN, M. Kant and the Exact Sciences. Cambridge, MA: Harvard University Press, 1992.

FRIEDMAN, M. Reconsidering Logical Positivism. Cambridge: Cambridge University Press, 1999.

FRIEDMAN, M. A Parting of the Ways: Carnap, Cassirer, and Heidegger. Chicago: Open Court, 2001.

GEROCH, R.; JANG, P.S. Motion of a body in general relativity. Journal of Mathematical Physics, v. 16, pp. 65-67, 1975.

HAACK, S. Carnap's Aufbau: Some Kantian Reflexions. Ratio, v. 19, pp. 170-176, 1977.

HOWARD, D. Relativity, Eindeutigkeit, and Monomorphism: Rudolf Carnap and the Development of the Categoricity Concept in Formal Semantics. In: GIERE, R.N., RICHARDSON, A.W. (eds.). Origins of Logical Positivism. Minneapolis: University of Minnesota Press, pp. 115-164, 1996.

KANT, I. Critique of Pure Reason. New York: St. Martin's, 1781 (1965).

MORMANN, T. New Work for Carnap's Quasi-Analysis. Journal of Philosophical Logic, v. 38, pp. 249-282, 2009.

MORMANN, T. Toward a Theory of the Pragmatic A Priori: From Carnap to Lewis and Beyond. In: CREATH, R. (ed.). Rudolf Carnap and the Legacy of Logical Empiricism. Dordrecht: Springer, pp. 113-132, 2012.

NERLICH, G. The Shape of Space. Cambridge: Cambridge University Press, 1994.

REICHENBACH, H. The Philosophy of Space and Time. New York: Dover, 1928 (1957).

RICHARDSON, A. Carnap's construction of the world: The Aufban and the emergence of logical empiricism. Cambridge: Cambridge University Press, 1998.

RUNGGALDIER, E. Carnap's Early Conventionalism: An Inquiry into the Historical Background of the Vienna Circle. Amsterdam: Rodopi, 1984. 
SAUER, W. On the Kantian Background of Neopositivism. Topoi, v. 8, pp. 111-19, 1989.

UEBEL, T. Rediscovering the Forgotten Vienna Circle. Dordrecht: Reidel, 1991.

RECEBIDO: 23/03/2003

RECEIVED: 23/03/2003

APROVADO: $25 / 05 / 2005$

APPROVED: $25 / 05 / 2005$ 